\title{
Towards an Understanding of Social Entrepreneurship: Traits and Learned Behavior
}

\author{
Autumn Jaye Moore \\ California State University \\ Veena P. Prabhu \\ California State University
}

\begin{abstract}
The discourse surrounding social entrepreneurship has primarily focused on creating a concrete definition for the term both as a part of and separate from traditional entrepreneurship, and the prevailing literature has furnished theoretical studies on the characteristics of social entrepreneurs. However, given the emerging nature of this field there is a lack of empirical research studies that validate some of the proposed theories. This paper will address this gap in the literature by provide empirical research on the fundamental traits and learned behaviors of social entrepreneurs by providing a conceptual model and empirically testing the direct effects. The findings of the current study provided evidence for altruism, perseverance, global risk taking, and social-entrepreneurial self-efficacy. They all have a direct and positive relationship with social entrepreneurial intent. The paper will conclude by outlining the agenda for future research, particularly the relationship between the identified characteristics and social impact.
\end{abstract}

\section{INTRODUCTION}

Social entrepreneurship is an emerging field of academic study (Robertson, Mair \& Hockarts, 2009; Weerawardena \& Mort 2006); The subject of social entrepreneurship first came about in the 1980s, and for the past 20 years it has had an evolving and mutable classification: civic entrepreneurship (Henton, Melville \& Walesh,1997), public sector entrepreneurship (Borins, 2000), entrepreneurship in the social sector (Austin, Skillern, Leonard, \& Steverson, 2007), a socially entrepreneurial organization (Robertson, Mair \& Hockarts, 2009), a social enterprise (Crossan, Bell \& Ibbotson, 2003), a socially-oriented venture (Certo and Miller, 2008; Roman-Calderon, Odaoardi \& Battistelli, 2015), a social organization (Sullivan Mort, Weerawardena, \& Carnegie, 2003), a social business (Kickul, Tejerson, Bacq, \& Griggiths, 2012), and a microenterprise. The term social entrepreneurship has been in more frequent circulation in academic and business circles since the early 2000s (Sastre-Castillo, Peris-Ortiz, Danvila-Del Valle, 2015).

The most often quoted researchers on the subject are Dees (1998); Austin, Stevenson, and WeiSkillern (2006); Drayton (2002); Nicholls, (2010); Weerawardena and Mort (2006); and Boschee (1998). Dees (1998) coined the leading definition for social entrepreneurship and the social entrepreneurs that lead these organizations, identifying the latter in terms of five behavior-related characteristics: 
"Social entrepreneurs are transformative agents that behave according to the following patterns: '(i) adopting a mission to create and sustain social value (not just private value); (ii) recognizing and relentlessly pursuing new opportunities to serve that mission; (iii) engaging in a process of continuous innovation, adaptation, and learning; (iv) acting boldly without being limited by resources currently in hand, and; (v) exhibiting a heightened sense of accountability to the constituencies served and for the outcomes created"" (as cited in Austin, 2004, p. 65).

Austin, Stevenson and Wei-Skillern (2006), and Boschee (1998) provide criteria to distinguish between commercial entrepreneurship and social entrepreneurship on the merits of their business strategy, the latter researcher drawing on case studies. Drayton (2002) developed criteria and an organization to identify social entrepreneurs around the globe. Nicholls (2010) edited a comprehensive book that draws from an international cache of leading academics, policy makers, and practitioners to provide a definition for social entrepreneurship. Weerawardena and Mort (2006) provide a multidimensional model of social entrepreneurship.

Overall, the primary focus has been on defining the social entrepreneurship in comparison with traditional entrepreneurship (Sharira \& Lerner, 2006) and "understanding the business, how it operates and can operate more successfully, and the role of the individual entrepreneurial figure within this" (Muñoz, 2010, p. 303). The social entrepreneur is thus defined in terms of what they must do for the success of the enterprise (Choi \& Gray, 2008), and they are grouped in with traditional entrepreneurs when it comes to the factors that explain their entrepreneurial behavior (Sastre-Castillo, Peris-Ortiz, Danvila-Del Valle, 2015). Austin et al. (2006), Cukier et al. (2011), Martin and Osberg (2007), and Zahra, Gedajlovic, Neubaum, and Shulman (2009) cast them as simply the "people who solve social problems" (as cited in Sastre-Castillo, Peris-Ortiz, Danvila-Del Valle, 2015 p 352). There is substantial research on social entrepreneurs as individual leaders with internal motivations, traits and behaviors, as well as external challenges (Othman \& Ab Wahid, 2014; Sastre-Castillo, Peris-Ortiz, Danvila-Del Valle, 2015; Aileen Boluk \& Mottiar, 2014; Bragaa, Proençab \& Ferreira, 2014; Smith and Woodworth, 2012), but few have been empirical (Aileen Boluk \& Mottiar, 2014) and most have created an identity profile for social entrepreneurs by comparing them to their commercial counterparts or connecting them with their organization's mission and offerings (Robinson, Mair, \& Hockerts, 2009; Zahra et al. 2009).

\section{Social Entrepreneurship and Social Enterprise}

Social entrepreneurship may result in an enterprise or business endeavor "dedicated to solving social, economic, and environmental problems" (Yunus, 2011, vii). In comparing the vast array of business ventures to a spectrum, these organizations lie in between the far left - not-for-profit organizations, philanthropic foundations, and nongovernmental organizations - and the far right - traditional entrepreneurship such as small business creation, startup enterprises, etc. (Abu-Saifan, 2012). Like nonprofit organizations, social enterprises work to enhance the social good; however, they are profit generating organizations that aim to be self-sufficient and promote long-term sustainability (Noruzi, Westover, \& Rahimi, 2010; Abu-Saifan, 2012). "Their focus on business practice means social enterprises are much less reliant than charities and voluntary organizations on the collection of donations and grants" (Muñoz, 2010, p. 302). Traditional entrepreneurship shares a common definition with social enterprises: "The opportunistic pursuit of economic wealth via creative initiatives of the individual operating within an uncertain environment constrained by limited tangible resources" (Nga \& Shamuganathan, 2010, p. 260).

The opportunity for social enterprises are 'social market failures', which are created by the inefficient distribution and provision of public/social goods to address issues such as poverty, access to healthcare and education, disaster preparedness, human rights abuses, etc. (Robinson, Mair, \& Hockerts, 2009). However, the mission of a social enterprise is to support equity and achieve systematic social change (Austin, 2004); the creative initiative is to cause a paradigm shift, and its wealth is the attainment of improved social value rather than financial gain. In response to limited resources, social enterprises often use nontraditional or underutilized tools to tackle problems, relying on tools such as music, 
bioconstruction, and new information technologies, as well as unique business structures such as social partnerships, co-operatives and hybrid models (Austin, 2004; Dees, Emerson, Economy, 2004). Lastly, social enterprises rely on the involvement and empowerment of the community they serve in order to help members proactively improve their own situation (Muñoz, 2010).

Seeing that social enterprises span both the profit and not-for-profit sectors and their area of interest is just as varied, it is true that social entrepreneurs must be adept in both business and philanthropic environments, and innovative in their ideas to address social ills. They must strike the right balance between addressing financial concerns and pursuing innovative marketing strategies, with meeting social objectives and retaining their social mission (Sullivan et al, 2003). Beyond this, social entrepreneurs must possess certain individual characteristics of "leadership, namely, significant personal credibility and ability to generate followers' commitment to the project by framing it in terms of important social values, rather than purely economic terms" (Sullivan et al, 2003, p. 79).

The theoretically identified elements of a social entrepreneur are creativity, courage and strength in the face of adversity, high levels of commitment, extroversion, agreeableness, conscientiousness, kindness, openness to new ideas, charisma, being self-demanding, and sensitivity to exclusion, marginalization, or suffering (Sastre-Castillo, Peris-Ortiz, Danvila-Del Valle, 2015; Nga \& Shamuganathan, 2010). What this study aims to do is create what Othman and Ab Wahid (2014) and Sastre-Castillo, Peris-Ortiz, and Danvila-Del Valle (2015) term a "social entrepreneur profile" that identifies the specific personal characteristics of social entrepreneurs (SPCSE) and their traits that contribute to their sustained success. For the purposes of this study, I identify both inborn traits and learned behavioral characteristics, recognizing that taking the "traditional personality trait-based 'born entrepreneur' approaches are inadequate to capture the behavioral characteristics of social entrepreneurs and the environment in which they operate", (Sullivan et al, 2003, p. 85) and that an entrepreneurial posture can be learned.

\section{Purpose}

The purpose of this study is twofold: Firstly, to propose a conceptual model with a focus on individual traits and learned behaviors that are integral to the success of social entrepreneurs. Secondly and more importantly to empirically test these antecedents (traits and learned behavior) on social entrepreneurial intention.

\section{CONCEPTUAL MODEL}

Past research has discussed several antecedents of social entrepreneurs and particularly interesting were the studies delineating traits and learned behaviors in the context of Latin America. Based on the extant literature I hypothesized a conceptual model wherein four traits-altruism, materialism, perseverance, and global risk taking — and two learned behaviors-deferred gratification and attitude towards government - were chosen.

As seen from Figure 1, I was interested in the mechanism by which these six variables affected social entrepreneurial intent (please note: for the pilot study my main dependent variable was social entrepreneurial intent but for validating the model in the Latin American context I used social impact as main dependent variable). Based on past research I included two contextual variables-social entrepreneurial self-efficacy and cultural values - anticipating a meditational framework (focuses on "how" a predictor relates to the dependent variable) for the former and a moderational framework (focuses on "when" and to what degrees of the moderating variable is there a relationship between predictor and dependent variable) for the latter in their relationship with social entrepreneurial intention. 


\section{FIGURE 1 \\ CONCEPTUAL MODEL FOR SOCIAL ENTREPRENEURS}

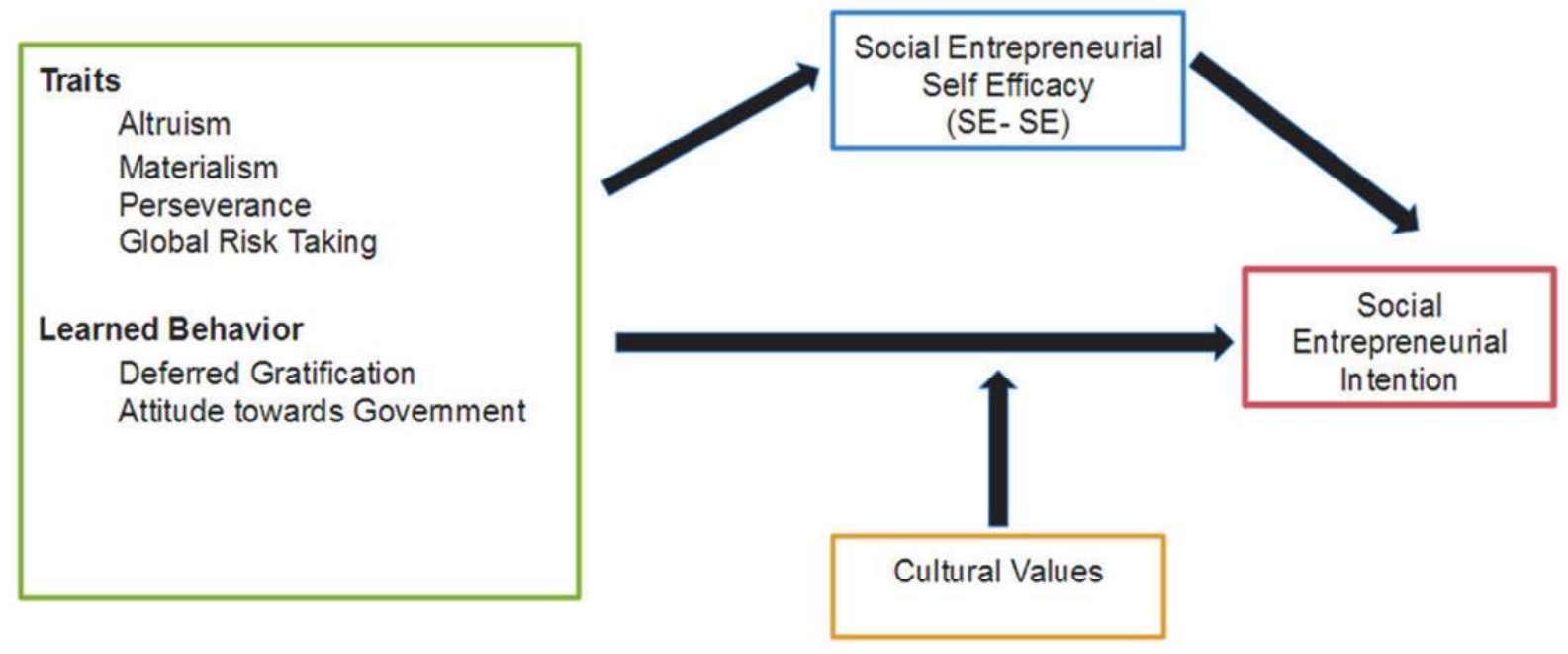

\section{HYPOTHESES}

\section{Social-entrepreneurial Intention}

For the pilot study I chose social entrepreneurial intention as the main dependent variable give that the study sample included students. Mcguire (2003) provides the clearest and most oft cited definition of entrepreneurship: taking advantage of a market opportunity by transforming innovation into a new product, service or business. It involves innovating or improving upon a current innovation, and utilizing time, effort, money, and skills in order to seize and convert opportunities into marketable ideas: new products, processes, solutions, and services (Prabhu, McGuire, Drost, 2012). On a macroscale, entrepreneurship is connected with economic growth, social mobility, and job creation in both developed and transitional economies (Prabhu, McGuire, Drost, 2012). Entrepreneurs can be characterized as individuals who are risk-tolerant and seek autonomy, challenge, and an opportunity to be creative (Prabhu, McGuire, Drost, 2012).

The question arises: what leads to entrepreneurial behavior? Krueger and Carsrud (1993) cite entrepreneurial intent as the primary predictor of entrepreneurial behavior. To borrow from Ajzen (1991, p. 181):

Intentions are assumed to capture the motivational factors that influence a behavior; they are indications of how hard people are willing to try, of how much of an effort they are planning to exert in order to perform the behavior. As a general rule, the stronger the intention to engage in a behavior, the more likely should be its performance.

There is evidence that the choice an entrepreneur makes as to the type of business they form consistently follows after the initial idea to start a business (Brockhaus, 1987). Reynolds and Miller (1992) posit that it's easier to study individuals that began their entrepreneurial process with an initial business intention than those who did not. To define entrepreneurial intention, I here borrow from Katz and Gartner (1988) who broadly identified this intention as an individual's commitment to start a new business as well as Bosma

\section{Altruism and Materialism}

For this study, I used Stocks and Lishner's (2016) definition of altruism: a motivational state that influences an individual to protect or promote the welfare of another person. Altruism has been identified 
as a key motivation for individuals to initiate and maintain a social project (Bragaa, Proençab \& Ferreira, 2014). As a behavior that is prosocial in nature, it is essential for social entrepreneurs because they are described as community-centric, caring capitalists whose are driven by social motives more than personal aims (Boluk \& Mottiar, 2014). Typically, social entrepreneurs are less motivated by money, the gain of individual wealth and the commercial needs of communities, but rather by altruism, philanthropic motivations, and the social needs of communities (Aileen Boluk \& Mottiar, 2014). Thus, for a social entrepreneur the pursuit of material or monetary possessions is not their source of motivation. In fact, the accumulation of wealth is viewed as a means to end: generating mission-related impact (Dees 1998; Aileen Boluk \& Mottiar, 2014) This leads to my inclusion of materialism, defined as a set of centrally held beliefs about the importance of possessions and monetary success is in one's life, and the degree to which material aims are pursued in comparison to the spiritual (Richins \& Dawson, 1992) in my conceptual model. I broaden the definition from the desire to possess material goods, and associate the term with the personality traits it engenders that put it in contrast with the self-less traits altruism: possessiveness, non-generosity, and envy (Belk, 1984).With these considerations, I anticipate the following:

\section{Hypothesis 1: Altruism will have a positive and significant relationship on social entrepreneurial intention. \\ Hypothesis 2: Materialism will have a negative and significant relationship on social entrepreneurial intention.}

\section{Perseverance}

Perseverance is closely connected with its synonyms resilience and endurance. It is defined as an individual's ability to persist when a task is difficult or uninteresting; to complete projects or work under conditions where there is distracting stimuli (Whiteside and Lynam, 2001). Besides a range of self-started and proactive behaviors, initiative involves persistent behavior (Frese \& Fay, 2001) such as demonstrating perseverance in the face of obstacles (Rank, Pace, \& Frese, 2004). Social entrepreneurs, unlike their commercial counterpart face a wide array of obstacles-from seeking consistent funding to inspiring volunteers to join and work in their social enterprise. Sharira and Lerner (2006) have aptly stated that "essential to the founding and establishing of any social venture are the individuals and groups with the vision, drive and perseverance to provide answers to social problems and needs" (p. 4). Hence I anticipated that perseverance will indeed have an impact on one's social entrepreneurial intent.

Hypothesis 3: Perseverance will have a positive and significant relationship on social entrepreneurial intention.

\section{Global Risk Taking}

Risk taking is the willingness to participate in activities that are known to be dangerous or have potential hazards associated with them. (Westaby \& Lee, 2003). As a concept, it is indispensable to the fields of creativity and traditional entrepreneurship (Prabhu, 2011). For commercial entrepreneurship, it has been proposed that innovativeness, achievement motivation, and a proclivity for risk taking are integral characteristics of entrepreneurs. (Faragó, Kiss, Boros, 1998). The social-value generating products and services offered by social entrepreneurs and their enterprise(s) fill the void left by institutions that shy away from such offerings because of the prevailing view that the risk associated with such aims is potentially too excessive in comparison to the anticipated profit (Sastre-Castillo, Peris-Ortiz, and Danvila - Del Valle, 2015).

Further, in a sampling of social entrepreneur characteristics taken from specialized literature, (SastreCastillo, Peris-Ortiz, and Danvila - Del Valle, 2015) the ability to assume a high level of risk is highlighted as an identifiable characteristic. Therefore, in connection with social entrepreneurs, risktaking involves more than being able to balance opportunities with the risks involved, or being risktolerant (Austin et al, 2006), but rather being drawn to taking risks for the sake of the greater good and the achieving the very definition of social entrepreneurship. Considering that social entrepreneurship 
addresses the macro-level issues plaguing society and their endeavors are scalable in the global context, I have identified the propensity for global risk taking as a key predictor for social entrepreneurial intent.

Hypothesis 4: Global risk taking will have a positive and significant relationship on social entrepreneurial intention.

\section{Deferred Gratification}

Deferred gratification, or delayed gratification is the ability to abstain from or wait for something until such time as it can be obtained. When faced with the decision between an immediately available option or a delayed alternative, the latter of which will typically be the most beneficial in the long run, it is the choosing of the delayed alternative. It is the foundation of traditional entrepreneurship, evident in an entrepreneur's deprivations, savings, and investing for the purpose of cultivating and sustaining their small enterprise (Dollinger, 2012). Deferred gratification requires willpower, impulse control, and most relatedly self-control and self-regulation (Dollinger, 2012). Self-control, which is defined as "the regulation of behavior so as to facilitate progress towards key goals" (RA Baron et al., 2016, p.57), is related to goal creation, pursuit, perseverance, and attainment, and subsequently the performance of a firm or enterprise. In this area, the profile of a commercial and social entrepreneur intersects, as they both are goal-driven and must

Hypothesis 5: Delayed gratification will have a positive and significant relationship with social entrepreneurship.

\section{Attitude Towards Government and Social Problems}

Social entrepreneurs step in where there is a lack of funding or lack of attention given to address social problems, especially on the part of the government. They also play a vital role in ameliorating adverse social conditions, especially in underdeveloped and emerging economies where resource scarcity and corruption among governments and even NGOs severely limit the attention given to serious social needs (Zahra et al., 2009). Evidently, social entrepreneurs are not passive or contented in reference to the government's actions, nor are they able to ignore the faults of the government systems that their communities or countries operate under.

Hypothesis 6: A negative attitude towards government will have a positive relationship with social entrepreneurship.

\section{Social-Entrepreneurial Self-Efficacy}

Self-efficacy is the belief in one's own abilities to succeed. When applying this term to entrepreneurship, it is a person's belief in their ability to launch a successful entrepreneurial venture and/or in their capability to assume the role and tasks of an entrepreneur (Bird, 1988; Stephen, Hossain, \& Monsour, 2009). The benefits of entrepreneurial self-efficacy in terms of research are that the level of entrepreneurial self-efficacy has been proven to serve as a strong predictor of one's level of entrepreneurial intentions and ultimately action (Stephen, Hossain, \& Monsour, 2009); it represents a central mechanism of personal agency; it incorporates personality and environmental factors; and it influences an individual's level of effort and persistence (McGee, Peterson, Mueller \& Sequeira, 2009).

Smith and Woodward (2012) draw from the definition and application of entrepreneurial self-efficacy to coin the term social entrepreneurial self-efficacy (SESE), and identify a connection between SESE and social entrepreneurial intentions, particularly among students. In their study, they indicate that a high level of social entrepreneurial self-efficacy, which they define as "a belief in one's ability to effect positive social change", will predispose an individual to take part in activities aimed at creating social value, will persevere in these efforts, and will do well in them (p. 393). To continue, the results of Zhao, Seibert, and Hill's (2005) study on the mediating role of self-efficacy on students entrepreneurial intentions supported the critical mediating role of entrepreneurial self-efficacy in the relationship between three of the most frequently identified individual-level antecedents of entrepreneurship and subsequent intentions to become an entrepreneur. Extending this to the context of social entrepreneurship, I anticipate 
that SESE can also have a mediating effect on the relationship between the identified traits /learned behaviors and social entrepreneurial intention.

Hypothesis 7: Social Entrepreneurial self-efficacy will have a positive and significant relationship with social entrepreneurial intent.

\section{Cultural Values}

Culture in itself encapsulates the shared beliefs, values, behavioral norms, and patterns of action of a group of individuals in a community, organization or nation that are passed on to others (Nguyen and Truong, 2016; Stephen, Hossain \& Monsour, 2009; Witte, 2013). Specifically, cultural values "represent the implicitly or explicitly shared abstract ideas about what is good, right, and desirable in a society", such as freedom, prosperity, security (Schwartz, 1999, p. 25).

Kluckhohn and Strodtbeck (1961) provide an overarching description of culture: how societies respond to five universal questions indicates their value orientations; culture is the individual or societal variations of these five value orientations (Stephen, Hossain \& Monsour, 2009). Kluckhohn and Strodtbeck (1961) identify the following as universal questions:

1. What is the character of human nature - are people basically good, evil, or both? Can people change?

2. What is the relation of humans to nature and the supernatural; should humans subjugate themselves to, live in harmony with, or attempt to master nature and the supernatural?

3. What is the temporal focus of human life - past, present, or future?

4. What is the preferred mode of activity - being, becoming, or doing?

5. How should humans relate to others; are humans individualists or collectivists? (as cited in Stephen, Hossain \& Monsour, 2009 p?)

Hofstede's (1980) national culture's framework also describes culture as a variation, but in this case on four or more identified dimensions: Individualism / Collectivism, Power Distance, Uncertainty Avoidance, and Masculinity / Femininity (Stephen, Hossain \& Monsour, 2008). Using these models, Stephen, Hossain \& Monsour, (2009) provide identify six relevant cultural values: doing vs. being orientation, determinism vs. free will, power distance, uncertainty acceptance vs. uncertainty avoidance, individualism vs. collectivism, and facework. In their study, doing vs. being is defined as the value placed on work itself, exertion to reach goals, accomplishments, and goal achievement in comparison with leisure, family and social life. Doing cultures tend to value the former more than the latter, and it is reversed for the being cultures.

Determinism vs. free will can be closely connected with attributional uncertainty, and these cultural beliefs can affect exertion, innovativeness, and aptness to accept new ideas. The level of power distance, or "the extent to which people are comfortable with distances (inequality) in power and status among members of society", that is evident in a culture can predict productivity, economic creativity, the number of innovations, the proposing of novel ideas, resistance to unethical behavior evident in superiors, and the ability to challenge the status quo (p. 10). A culture's uncertainty avoidance or acceptance influences how much they value rules development, rule following, and new idea generation.

Individualistic and collectivistic cultures differ in their tendencies to encourage in-group cooperation or competition, and to accept or reject unethical decisions that affect their group. Facesaving refers to the degree to which individuals in a culture value the protection of ego, either their own or that of other peoples', during communication. Noteworthy in this study is that these six identified cultural values and beliefs were measured on a continuum from low to high, indicating that varying levels of these cultural values exert differential effects on the relationship between the predictors and the dependent variables.

In other studies, culture has been shown to correlate and sometimes predict individual and group outcomes and behaviors by providing an explanation for such things the decision-making process and perceptions of business executives, the varying approaches to work and management, business decisions on an international scale, and an individual's willingness to accept changes in the status quo (Stephen, 
Hossain \& Monsour, 2009). The apparent ability of cultural values to explain the why indicates that it has moderating effects (Stephens, Hossain \& Monsour, 2009).

Research on general and specific cultural values as moderators have been studied, ranging from the moderating effect of individualism/collectivism in the relationship between efficacy, perceived uncertainty, or decision-making, and performance (Kirkman, Lowe \& Gibson, 2006), to the moderating effect of power distance and traditionality on relationships between perceived organizational support and work outcomes (Farh, Hackett \& Liang, 2007).

Further, in the field of entrepreneurship, culture has been shown to have a profound impact on aspects of entrepreneurship, but the direct or moderating effects of culture on social entrepreneurship or social entrepreneurial intent have not been explored in depth (Witte, 2013). This study attempts to address this little studied area, and in it we anticipate that culture will have a moderating role on the aforementioned predictors and social entrepreneurial intent.

Hypothesis 8: Cultural Values will have a positive and significant relationship with social entrepreneurial intention.

\section{METHODOLOGY}

\section{Data Sample}

My pilot study sample is comprised of 279 survey responses, only 245 of which were usable due to missing or incomplete data. The respondents were undergraduate students at a large university and the students all came from a variety of disciplines, the predominant ones being business, political science, psychology, communications, biology, sociology, social work, computer science, nursing, and public health. University students were chosen for my sample to measure social entrepreneurial intent because they have not yet started a social enterprise but are likely to do so, and in the research on traditional entrepreneurship, they have the empirically highest entrepreneurial inclination (Prabhu, McGuire \& Drost, 2012).

\section{Data Collection}

As mentioned earlier, to validate the conceptual model I conducted a pilot study-the results of this pilot study will be included in this thesis. Simultaneously I am also collecting data from social entrepreneurs located in Latin America. I used two different questionnaires; for the pilot study on students, I distributed a paper and pencil version in a classroom setting [see Appendix 1], while for the main study on social entrepreneurs I created an electronic questionnaire using Qualtrics and invited them to participate via email [see Appendices 2 and 3]. The questionnaire for the pilot study tested for the nine items: altruism, materialism, deferred gratification, perseverance, global risk taking, attitude towards government, social problems, social entrepreneurial self-efficacy, and culture. The main study incorporates these variables and also includes life satisfaction, job satisfaction, perceived organizational support, reputation, and political skills, which totals fifteen items. For the pilot study, given that my sample were students, the dependent variable is social entrepreneurial intention while for the main study on current social entrepreneurs in Latin America I have used social impact as my main criterion variable.

\section{Measures}

Social Entrepreneurial Intention

The main dependent variable was measured using a scale developed for this study. The scale included 7 items with two items each focusing on measuring if the respondent was (a) interested in starting a business to solve a social problem; (b) join or start networks of people interested in solving social problem and (c) develop a sustainable business model (which was not dependent on charity or government. Furthermore, the seventh items specifically aimed at measuring the "type" of social issue they would address first. Using a 7-point Likert scale (for all items) the question read: "How likely - in the next 5 years - it is that you will take action to address the following social problems?" with the following choices: Animal Rights; Corruption and Good Government; Local Community Issues; 
Environment (Climate change, pollution, etc.); Human Rights and Human Health. I also included one more item to that differentiated between social entrepreneurship and social employment with the former focusing on social issues and or starting a business or non-profit to solve a social problem while later although concerned social issues was more related to working for government or a non-profit job to address a social problem. We found a robust reliability (Cronbach's $\alpha=.87$ ).

\section{Altruism}

Altruism was measured using a seven item scale. Items included "Most people would stop and help a person whose car is disabled", "Most people do not hesitate to go out of their way to help someone in trouble". Respondents indicated their level of agreement or disagreement with the give items on a sevenpoint scale that was reverse-coded with $7=$ strongly agree and $1=$ strongly disagree so that the responses measured perseverance rather than the lack of it. Cronbach's alpha measured .71

\section{Global Risk-Taking}

To measure global risk taking I used the five item scale prepared by Westaby and Lee's (2003) . Items included "I love to take risks even when there is a small chance I could get hurt", "I value having fun more than being safe. Respondents indicated their level of agreement or disagreement with the give items on a seven-point scale that was reverse-coded with $7=$ strongly agree and $1=$ strongly disagree so that the responses measured perseverance rather than the lack of it. Cronbach's alpha measured .83

\section{Materialism}

Materialism was measured by using one of the subscales from the material values scale, which was developed by Richins and Dawson (1992) and adapted to a short version by Richins in 2004. Items used included "I put emphasis on material things than most people I know", "I admire people who own expensive homes, cars and clothes. Respondents indicated their level of agreement or disagreement with the give items on a seven-point scale that was reverse-coded with $7=$ strongly agree and $1=$ strongly disagree so that the responses measured perseverance rather than the lack of it. Cronbach's alpha measured .71

\section{Perseverance}

To measure perseverance, we used one of the four subscales of the UPPS Impulsive Behavioral Scale, which is a forty-five item inventory designed to measure the pathways to impulsive behavior. One of the pathways, (lack of) perseverance, gauges persistence in a task when boredom or fatigue is present. Respondents indicated their level of agreement or disagreement with the ten items on a seven-point scale that was reverse-coded with $7=$ strongly agree and $1=$ strongly disagree so that the responses measured perseverance rather than the lack of it. Cronbach's alpha measured .81

\section{Deferred Gratification}

In the present study deferred gratification was defined as "Ability to resist the temptation for an immediate reward in order to receive a larger or more enduring reward later" (Walter, Ebbe and Antoinnette, 1972, p. 33) and was measured using their 6 item scale. Using a 7-point Likert scale we used items for example: "If my favorite food were in front of me, I would have a difficult time waiting to eat it." "I prefer to explore the physical side of romantic involvements right away." "I enjoy spending money the moment I get it." We found marginal reliability (Cronbach's $\alpha=.65$ )

\section{Negative Attitude towards Government}

It was measured using a scale prepared for this study. For this 3-item scale we used a 7-pont Likert scale. One of the items were "government is useless to solve social problems". We found marginal reliability (Cronbach's $\alpha=.59$ ) 


\section{Social Entrepreneurial Self-efficacy}

It was defined as the confidence in one's ability to perform the roles and tasks of a social entrepreneur and was measured using their 12 item scale. Using a 7-point Likert scale we used items for example: "Identify opportunities"; "Create new products or services"; "Launch a sustainable new venture"; "Really make a difference and solve a problem!" We found a robust reliability (Cronbach's $\alpha=$ $.90)$.

\section{Cultural Values}

There are several frameworks and methodological approaches to describing and assessing cultural values. We sought to measure individual-level variations in values, rather than to examine societal-level cultural differences, recognizing that while there should be commonalities, there would also be significant variation among respondents from the same cultural backgrounds.

In the present study, cultural values were measured as individual-level phenomena on a continuum from low to high, thus representing the degree to which a given individual expressed a certain value. While aggregates (properly calculated) of individuals belonging to the same group (say, a society) do express meaningful generalizations, individual variations may be significant even within the most cohesive group.

The scale included subscales (1) Determinism vs. Free Will - The extent to which people believe that external forces (fate or a Superior Being) control what happens to them (Determinism) rather than believing that people are able to control the consequences of their actions (Free Will)( Cronbach's $\alpha=$ .82); (2) Facework - The tendency of members of a culture to protect either their own egos when they communicate or to protect the ego of others with whom they communicate; the degree to which members of a culture place value on saving face. (Cronbach's $\alpha=.68$ ). (3) Individualism vs. Collectivism - The extent to which people value achievement of goals and status individually rather than through group membership; the degree to which a person's identity is largely shaped by the groups to which one belongs (Collectivism) rather than defined apart from these groups (Individualism)(Cronbach's $\alpha=.60$ ).

\section{Control Variable and Demographic Data}

Age has in some cases been shown to be associated with entrepreneurship (Hsu et al., 2007) but not in others (Kristiansen \& Indarti, 2004), and there appears to be a tendency since the 1950s for people to begin entrepreneurship at an earlier age (Hsu et al., 2007). Therefore, I used age as a control variable when testing hypotheses. Age did not correlate with the measures. Note in the given sample of students the range in age was from.

In addition to age, we collected information on college program of study (major field). I found no significant differences between the different majors in the student sample or via on any of the variables in the study.

\section{RESULTS}

\section{Descriptive Statistics}

Table 1 displays means, standard deviations and correlations among all the variables. Social entrepreneurial was significantly and positively related to altruism $(r=.15, p=.01)$, perseverance $(r=$ $.21, p=.001)$ and global risk taking $(r=.22, p=.000)$ and social entrepreneurial self-efficacy $(r=.46, p$ $=.000)$. Materialism, positive attitude towards government, deferred gratification and cultural values did not have a significant relationship with social entrepreneurial intention. 
TABLE 1

DESCRIPTIVE STATISTICS AND ZERO-ORDER CORRELATIONS AMONG VARIABLES

\begin{tabular}{|c|c|c|c|c|c|c|c|c|c|c|c|}
\hline & Variables & $M$ & $S D$ & 1 & 2 & 3 & 4 & 5 & 6 & 7 & 8 \\
\hline 1 & $\begin{array}{l}\text { Social } \\
\text { Entrepreneurial } \\
\text { Intention }\end{array}$ & 5.0 & 1.0 & & & & & & & & \\
\hline 2 & $\begin{array}{l}\text { Social } \\
\text { Entrepreneurial } \\
\text { Self - Efficacy }\end{array}$ & 4.9 & 1.2 & $0.5^{* *}$ & & & & & & & \\
\hline 3 & $\begin{array}{l}\text { Cultural } \\
\text { Values }\end{array}$ & 3.9 & 0.7 & 0.1 & 0.1 & & & & & & \\
\hline 4 & Altruism & 3.7 & 1.4 & $0.2^{*}$ & 0.1 & $0.3^{* *}$ & & & & & \\
\hline 5 & Materialism & 3.4 & 1.2 & 0.0 & 0.0 & 0.0 & 0.0 & & & & \\
\hline 6 & Perseverance & 5.8 & 0.9 & $0.2^{* *}$ & $0.4^{* *}$ & 0.0 & 0.0 & -0.1 & & & \\
\hline 7 & $\begin{array}{l}\text { Global Risk } \\
\text { Taking }\end{array}$ & 4.1 & 1.5 & $0.2^{* *}$ & $0.4^{* *}$ & 0.0 & 0.0 & 0.1 & $0.1^{*}$ & & \\
\hline 8 & $\begin{array}{l}\text { Deferred } \\
\text { Gratification }\end{array}$ & 3.2 & 1.1 & -0.1 & $-0.2 * *$ & $0.2 * *$ & $0.1^{*}$ & $0.4^{* *}$ & $-0.3 * *$ & -0.1 & \\
\hline 9 & $\begin{array}{l}\text { Attitude } \\
\text { Towards } \\
\text { Government }\end{array}$ & 4.2 & 0.8 & 0.0 & 0.0 & $0.2^{* *}$ & 0.0 & 0.0 & 0.1 & 0.0 & 0.1 \\
\hline
\end{tabular}

Note. $N=245$

${ }^{*} p<.05 .{ }^{* *} p<.01$.

\section{Hypotheses Testing}

For the pilot study I found support for Hypothesis 1 which posited the positive relationship between altruism and social entrepreneurial intention $(\beta=.15, p<.01)$. Similarly hypotheses 3,4 , and 7 were supported which related to perseverance $(\beta=.21, p<.01)$; global risk taking $(\beta=-.22, p<.00)$; and social entrepreneurial self-efficacy $(\beta=.48, p<.00)$ respectively. I did not find support for hypotheses 2 , 5,6 and 8 wherein I anticipated a positive relationship between materialism, deferred gratification, and social entrepreneurial intention respectively.

\section{DISCUSSION}

Social entrepreneurship has emerged as "a central tenet of economic and regional development strategies" (Howorth, Smith \& Parkinson, 2012, p. 371) especially in areas of underdeveloped and developing countries (Parkinson, 2011). In this study I have particularly focused on the Latin American context. Furthermore, social entrepreneurship being a nascent field has (Weerawardena \& Mort Sullivan, 2006). The purpose of this study was therefore was twofold: propose a conceptual model for the traits and learned behaviors that are integral to the success of social entrepreneurs, validate the model by means of a pilot study conducted on students, and subsequently test whether the model is applicable in the context of Latin AM. This study provided empirical evidence for the relationship between social entrepreneurial intent and altruism, perseverance, global risk taking, and social-entrepreneurial self-efficacy. These factors have a positive relationship with social entrepreneurial intent through social entrepreneurial selfefficacy. Therefore, how altruistic an individual is, how keen they are to take risks, etc. will affect their intentions to become social entrepreneurs based on their self-efficacy levels. For example, if an individual 
is highly altruistic, is keen to take large scale risks, and is high in endurance, they are more likely to choose to become social entrepreneurs, particularly if they are highly confident in their ability to be one.

As an area of study, entrepreneurship and specifically social entrepreneurship are growing in popularity as academic areas of study. Business schools at both the undergraduate and graduate level offer degrees in entrepreneurship, and some universities, such as Duke University, Yale University, Babson College, Brigham Young University, and Sterling College have committed colleges and programs for social entrepreneurship, while others are starting to follow suit in response to increasing student interest in socially-oriented ventures (Mars \& Garrison, 2009). Smith \& Woodward (2012) posit that by using the social entrepreneurship and self-efficacy approach to social entrepreneurship, social entrepreneurship and social innovation education can provide students with the opportunity to become capable social entrepreneurs and innovators. One step in this approach is to provide examples of the archetypal characteristics, qualities, and attributes of social entrepreneurs that distinguish this group of individuals from other groups, such as philanthropists or activists (Smith \& Woodward, 2012). This study has empirically identified a profile for social entrepreneurs that consist of three traits and one learned behavior, all of which can be incorporated in the type of social entrepreneurship approach Smith and Woodward (2012) describe, and therefore can serve as a prototypical model for students to emulate.

In the business world, corporate social responsibility initiatives and the hybrid organizations that often result require employees who are aligned to the venture or programs specific value orientations, are committed to the mission, and who thus possess elements of a social entrepreneur (Roman-Calderon, Odaoardi \& Battistelli, 2015). In order to develop this type of employee, managers should build a climate that enhances self-efficacy, as this study has demonstrated its strong correlation with social entrepreneurial intent, and this behavior also increases an employee's intrinsic motivation and creativity (Prabhu, Sutton, Sauser, 2008).

\section{Limitations of the Study}

The determinant for this study was social entrepreneurial intention rather than behavior or the drivers of success in a social entrepreneurship, which I define as the achievement of social impact. Of note is that I do not claim that intent is related to subsequent social impact. My main study will extend to actual social entrepreneurial behavior and social impact. Further, my predictors did not include social entrepreneurship.

The scope of the study was limited to undergraduate students at one university-hence may raise some concern related to generalizability.

With behavioral studies, it is best to have more than one source to corroborate the accuracy of my measures. In this study, I relied on only one measure - the questionnaire - which puts the findings at risk of common method variance. Also, although present in the questionnaire, the study did not include nor test for the control variables: gender, age, nationality, etc.

\section{Future Research}

The insight gained from the qualitative findings can be used to refine the conceptual model that applies to current social entrepreneurs. The subsequent main study will have nascent and established social entrepreneurs as respondents, it will extend the number of predictors to include life satisfaction, job satisfaction, perceived organizational support, reputation, and political skills, and it will test for social impact. The study will provide insights into the global, regional, communal, and personal factors that affect the performance and outcomes of social entrepreneurs in Latin America. 


\section{CONCLUSION}

Social entrepreneurship is "a process by which citizens build or transform institutions to advance solutions to social problems." Social entrepreneurs are more than the orchestrators of this process or the leaders of social enterprises, and they are distinct from commercial entrepreneurs in their motivations, focus, and characteristics. Thus, this paper set out to identify a social entrepreneurial profile that identified the essential traits and learned behaviors of social entrepreneurs. A model was proposed and validated on students to ascertain its validity and gauge social entrepreneurial intent. From my findings, it is evident that altruism, perseverance, global risk taking, and social-entrepreneurial self-efficacy are integral elements of a social entrepreneur. The ongoing main study will further develop and test the model in the context of Latin America, with the determinant being the social impact generated by current social entrepreneurs.

\section{REFERENCES}

Aileen Boluk, K., \& Mottiar, Z. (2014). Motivations of social entrepreneurs: Blurring the social contribution and profits dichotomy. Social Enterprise Journal, 10(1), 53-68.

Ajzen, I. (1991). The theory of planned behavior. Organizational Behavior and Human Decision Processes, 50(2), 179-211.

Alter, S. K. (2003). Social Enterprise: a typology of the field contextualized in Latin America.

Austin, J. E. (Ed.). (2004). Social partnering in Latin America: Lessons drawn from collaborations of businesses and civil society organizations (Vol. 12). Harvard Univ David Rockefeller.

Austin, J. E., Skillern, J. W., Leonard, H., \& Steverson, H. (2007). Entrepreneurship In The Social Sector. In Meeting the Collaboration Challenge Workbook. Sage Publications.

Austin, J., Stevenson, H., \& Wei-Skillern, J. (2006). Social and commercial entrepreneurship: same, different, or both? Entrepreneurship theory and practice, 30(1), 1-22.

Auvinet, C., \& Lloret, A. (2015). Understanding social change through catalytic innovation: Empirical findings in Mexican social entrepreneurship. Canadian Journal of Administrative Sciences/Revue Canadienne des Sciences de l'Administration, 32(4), 238-251.

Belk, R. W. (1984). Three scales to measure constructs related to materialism: reliability, validity, and relationships to measures of happiness. Advances In Consumer Research, 11(1), 291-297.

Borins, S. (2000). Loose cannons and rule breakers, or enterprising leaders? Some evidence about innovative public managers. Public Administration Review, 60(6), 498-507.

Boschee, J. (1998). Merging mission and money: A board member's guide to social entrepreneurship. National Center for Nonprofit Boards.

Braga, J. C., Proenca, T., \& Ferreira, M. R. (2014). Motivations for social entrepreneurship-Evidences from Portugal. Tékhne, 12, 11-21.

Castellani, F., \& Lora, E. (2014). Is entrepreneurship a channel of social mobility in Latin America? Latin American Journal of Economics, 51(2), 179-194.

Certo, S. T., \& Miller, T. (2008). Social entrepreneurship: Key issues and concepts. Business Horizons, 51(4), 267-271.

Choi, D. Y., \& Gray, E. R. (2008). Socially responsible entrepreneurs: What do they do to create and build their companies? Business Horizons, 51(4), 341-352.

Crossan, D., Bell, J, \& Ibbotson, P. (2003). Towards a classification framework for social enterprises. In ARNOVA Conference.

Dees, J.G. (1998). The Meaning of Social Entrepreneurship. Kauffman Foundation and Stanford University.

Dees, J. G. (1998). Enterprising nonprofits. Harvard Business Review, 76, 54-69. 
Dees, J. G., Emerson, J., \& Economy, P. (2004). Strategic tools for social entrepreneurs: Enhancing the performance of your enterprising nonprofit (Vol. 207). John Wiley \& Sons.

Drayton, W. (2002). The citizen sector: Becoming as entrepreneurial and competitive as business. California Management Review, 44(3), 120-132.

Farh, J. L., Hackett, R. D., \& Liang, J. (2007). Individual-level cultural values as moderators of perceived organizational support-employee outcome relationships in China: Comparing the effects of power distance and traditionality. Academy of Management Journal, 50(3), 715-729.

Faragó, K., Kiss, O., \& Boros, J. (2008). Risk-taking in entrepreneurs, compared to criminals and students: The role of uncertainty and stakes. The Journal of Socio-Economics, 37(6), 2231-2241.

Frese, M., \& Fay, D. (2001). Personal initiative: An active performance concept for work in the $21^{\text {st }}$ century. In B. M. Staw \& R. M. Sutton (Eds.), Research in Organizational Behavior, (pp. 133187). Amsterdam: Elsevier Science.

Howorth, C., Smith, S. M., \& Parkinson, C. (2012). Social learning and social entrepreneurship education. Academy of Management Learning \& Education, 11(3), 371-389.

Jäger, U., Whittingham, K., Bamert, B., \& Rodriguez, A. (2013, April). Social Entrepreneurs in Latin America. Stephan Schmidheiny Innovation for Sustainability Award (Rep.).

Kickul, J., Terjesen, S., Bacq, S., \& Griffiths, M. (2012). Social business education: An interview with Nobel laureate Muhammad Yunus. Academy of Management Learning \& Education, 11(3), 453462.

Krueger, N. F., \& Carsrud, A. L. (1993). Entrepreneurial intentions: applying the theory of planned behaviour. Entrepreneurship \& Regional Development, 5(4), 315-330.

Layton, M. D. (2010). Philanthropy in Latin America. In International Encyclopedia of Civil Society (pp. 1201-1209). Springer US.

Lora, E. A., \& Castellani, F. (2014). Entrepreneurship in Latin America: A Step Up the Social Ladder? IDB Book No. IDB-BK-124.

Kirkman, B. L., Lowe, K. B., \& Gibson, C. B. (2006). A quarter century of culture's consequences: A review of empirical research incorporating Hofstede's cultural values framework. Journal of International Business Studies, 37(3), 285-320.

Madsen, K. M. (2013). Social Enterprise In Latin America: Dimensions of collaboration among social entrepreneurs. Center for Public Policy Administration Capstones. Paper 23.

Mars, M. M., \& Garrison, S. (2009). Socially-oriented ventures and traditional entrepreneurship education models: a case review. Journal of Education for Business, 84(5), 290-296.

McGee, J. E., Peterson, M., Mueller, S. L., \& Sequeira, J. M. (2009). Entrepreneurial self-efficacy: refining the measure. Entrepreneurship Theory and Practice, 33(4), 965-988.

Muñoz, S. A. (2010). Towards a geographical research agenda for social enterprise. Area, 42(3), 302-312.

Nga, J., \& Shamuganathan, G. (2010). The influence of personality traits and demographic factors on social entrepreneurship start up intentions. Journal of Business Ethics, 95(2), 259-282.

Noruzi, M. R., Westover, J. H., \& Rahimi, G. R. (2010). An exploration of social entrepreneurship in the entrepreneurship era. Asian Social Science, 6(6), 3.

Othman, N., \& Ab Wahid, H. (2014). Social entrepreneurship among participants in the students in free enterprise program. Education + Training, 56(8/9), 852-869.

Prabhu, V., Sutton, C., \& Sauser, W. (2008). Creativity and certain personality traits: Understanding the mediating effect of intrinsic motivation. Creativity Research Journal, 20(1), 53-66.

Prabhu, V. P. (2011). Risk-taking. In Encyclopedia of creativity, (Vol. 2, pp. 319-323). London, England: El Sevier.

Prabhu, V. P., McGuire, S. J., Drost, E. A., \& Kwong, K. K. (2012). Proactive personality and entrepreneurial intent: Is entrepreneurial self-efficacy a mediator or moderator? International Journal of Entrepreneurial Behavior \& Research, 18(5), 559-586.

Rank, J., Pace, V. L., \& Frese, M. (2004). Three avenues for future research on creativity, innovation, and initiative. Applied Psychology: An International Review, 53(4), 518-528. 
Richins, M. L., \& Dawson, S. (1992). A Consumer values orientation for materialism and its measurement: scale development and validation. Journal of Consumer Research, 19(3), 303-16.

Robinson, J., Mair, J., \& Hockerts, K. (Eds.). (2009). International Perspectives on Social Entrepreneurship. Palgrave Macmillan.

Robles, E. (2013). A New Kind of Social Entrepreneurship in Puerto Rico:'Mujeres Ayudando a Madres'. Review of Business \& Finance Studies, 4(2), 89-96.

Roman-Calderon, J. P., Odoardi, C., \& Battistelli, A. (2015). Cause-fit, positive attitudes and behaviors within hybrid Colombian organizations. Revista de Administração de Empresas, 55(4), 408-417.

Sastre-Castillo, M. A., Peris-Ortiz, M., \& Valle, D. D. (2015). What is different about the profile of the social entrepreneur? Nonprofit Management and Leadership, 25(4), 349-369.

Schwartz, S. H. (1999). A theory of cultural values and some implications for work. Applied Psychology: An International Review, 48, 23-47.

Short, J. C., Moss, T. W., \& Lumpkin, G. T. (2009). Research in social entrepreneurship: Past contributions and future opportunities. Strategic Entrepreneurship Journal, 3(2), 161-194.

Smith, I. H., \& Woodworth, W. P. (2012). Developing social entrepreneurs and social innovators: a social identity and self-efficacy approach. Academy of Management Learning \& Education, 11(3), 390407.

Sullivan, G., Weerawardena, J., \& Carnegie, K. (2002). Social entrepreneurship: Towards conceptualization. International Journal of Nonprofit \& Voluntary Sector Marketing, 8(1), 76.

Weeks, J. R., \& Seiler, D. (2001). Women's entrepreneurship in Latin America: An exploration of current knowledge. Inter-American Development Bank.

Weerawardena, J., \& Mort, G. S. (2006). Investigating social entrepreneurship: A multidimensional model. Journal of World Business, 41(1), 21-35.

Westaby, J. D., \& Lee, B. C. (2003). Antecedents of injury among youth in agricultural settings: A longitudinal examination of safety consciousness, dangerous risk taking, and safety knowledge. Journal of Safety Research, 34(3), 227-240.

Witte, C. T. (July 13, 2013). Cultural determinants of social entrepreneurship. (Master's thesis). Retrieved from http://thesis.eur.nl/pub/14087/MA-thesis-Caroline-Witte-371115.pdf 